\title{
Emergency severity index compared with 4-level triage at the emergency department of Ramathibodi University Hospital
}

\author{
Chaiyaporn Yuksen a, Sorravit Sawatmongkornkul ${ }^{\mathrm{a}}$, Supakrid Suttabuth ${ }^{\mathrm{a}}$, Kittisak Sawanyawisuth ${ }^{\mathrm{b}, \mathrm{c}}$, \\ Yuwares Sittichanbuncha ${ }^{\mathrm{a}}$ \\ ${ }^{a}$ Department of Emergency Medicine, Faculty of Medicine, Ramathibodi Hospital, Mahidol University, \\ Bangkok 10400, Thailand \\ ${ }^{b}$ Department of Medicine, Faculty of Medicine, Khon Kaen University, Khon Kaen 40002, Thailand \\ ${ }^{c}$ Research Center in Back, Neck, Other Joint Pain and Human Performance (BNOJPH), Khon Kaen \\ University, Khon Kaen 40002, Thailand
}

\begin{abstract}
Background: Emergency department (ED) triage is important for categorizing and prioritizing patients. Effective triage may assist in crowd reduction in the ED and appropriate patient management. There are several systems, including the 5-level Emergency Severity Index (ESI) and the 4-level Ramathibodi-nurse triage. Currently, there are limited data by which to compare the 5- versus 4-level triage; particularly on health outcomes, such as length of stay in the ED, mortality, and resource needs.

Objectives: To compare the accuracy of 5- and 4-level triage in an ED.

Methods: This observational study was conducted on a cross-section of patients in the ED at Ramathibodi Hospital of Mahidol University, Bangkok, Thailand. Eligible patients were those who visited the ED and were evaluated by ESI and nurse triage. Each evaluation was blinded to the results of the other. Discrimination performance between the 5- and 4-level triage was compared by using the area under a receiver operating characteristic (ROC) curve and concordance statistic for prediction of life saving intervention. Net reclassification improvement (NRI) of the 5-level ESI over the 4-level triage was performed.

Results: Study criteria were met by 520 patients. The areas under the ROC curves of the ESI and nurse triage on life-saving intervention were 92.2\% (95\% confidence intervals were 87.3\%, 96.9\%) and 81.3\% (95\% CI 75.2\%, 87.3\%), respectively. Areas under the ROC curve differed significantly $(P<0.001)$. The overall reclassification improvement was $42.4 \%$.

Conclusions: The 5-level emergency severity index was more accurate than the 4-level triage in terms of lifesaving intervention.
\end{abstract}

Keywords: Emergency room, ROC, triage

Triage at the emergency department (ED) is an important process by which to categorize and prioritize patients [1]. Effective triage may assist in crowd reduction in the ED and in appropriate patient management [2-5]. Physician response time to each patient depends on the individual patient category. The triage system was first described by the French physician, Dominique Jean Larrey, during the First World War. It was then developed for use in EDs worldwide [6].

Correspondence to: Yuwares Sittichanbuncha, Department of Emergency Medicine, Faculty of Medicine, Mahidol University, Bangkok 10400, Thailand.E-mail: yuwares.sit@mahidol.ac.th
There are several triage systems including the Emergency Severity Index (ESI), Australian Triage Scale, and Manchester Triage System [7, 8]. All triage systems are comparable in terms of effectiveness, but the ESI, widely used in the United States, seems to produce better values for validity, reliability, and inter-rater reliability [9-12]. The latest version of the ESI triage instrument (version 4), has 5 levels as follows: 1 -resuscitation, 2-emergency, 3-urgent, 4-less urgent, and 5-non urgent [3].

Ramathibodi Hospital is a major university and tertiary care institution located in central Bangkok, Thailand. All patients in the emergency room are initially evaluated by a triage nurse with years of 
experience. The nursing triage is divided into 4 levels; critical, emergency, acute, and general. To our knowledge, this triage system has never been fully validated or evaluated. A previous study showed that the 5-level ESI had better sensitivity and specificity than a 3-level version [3]. The sensitivity and specificity increased from $58 \%$ to $68 \%$ and $83 \%$ to $91 \%$, respectively, when the triage was changed from 3 to 5 levels. The under-triage rates were also lower in the 5 -level evaluation (12\% vs $28 \%$ ). Currently, there is limited data on directly comparing the 5- and 4-level triage at the ED, particularly on health outcomes such as length of stay in the ED, mortality, or resource needs during an ED visit.

\section{Materials and methods}

The study protocol was approved by the Institutional Review Board of Mahidol University (approval No. MURA2014/414). This observational study was conducted on a cross-section of patients in the ED in Ramathibodi Hospital, Mahidol University, Thailand. Eligible patients were patients who visited the ED and were evaluated by both the ESI (version 4), or 5-level ESI and the nurse triage. The ESI was performed by the emergency physicians on duty at the ED, while the nurse triage was evaluated by an ED nurse with at least 5 years of experience at the ED. Each evaluation was blinded to the results of the other. We excluded patients with incomplete medical data, referred patients, patients using the emergency medical service (EMS), and patients with appointments for vaccination or medications. Written informed consent to participate in the present study was given by all included patients or their nearest relatives.

Baseline characteristics of all patients were recorded. Additionally, 5 outcomes were evaluated including immediate life-saving intervention (LSI) (Table 1), resource needs, hospitalization rate, mortality rate, and length of stay at the ED.

Table 1. Immediate life-saving interventions at the emergency department*

\begin{tabular}{|c|c|c|}
\hline & Life-saving & Not life-saving \\
\hline Airway/breathing & $\begin{array}{l}\text { BVM ventilation } \\
\text { Intubation } \\
\text { Surgical airway } \\
\text { Emergency continuous positive airway pressure } \\
\text { Emergency bilevel positive airway pressure }\end{array}$ & $\begin{array}{l}\text { Oxygen administration } \\
\text { Nasal cannula } \\
\text { Non-rebreather }\end{array}$ \\
\hline Electrical therapy & $\begin{array}{l}\text { Defibrillation } \\
\text { Emergency cardioversion } \\
\text { External pacing }\end{array}$ & Cardiac monitor \\
\hline Procedures & $\begin{array}{l}\text { Chest needle decompression } \\
\text { Pericardiocentesis } \\
\text { Open thoracotomy } \\
\text { Intraosseous access }\end{array}$ & $\begin{array}{l}\text { Diagnostic Test } \\
\text { - Electrocardiography } \\
\text { - Laboratory test values } \\
\text { - Ultrasound } \\
\text { - Focused abdominal scan for trauma }\end{array}$ \\
\hline Hemodynamics & $\begin{array}{l}\text { Significant intravenous fluid resuscitation } \\
\text { Blood administration } \\
\text { Control of major bleeding }\end{array}$ & $\begin{array}{l}\text { Intravenous access } \\
\text { Saline lock for medications }\end{array}$ \\
\hline Medications & $\begin{array}{l}\text { Naloxone } \\
\text { Intravenous } 50 \% \text { dextrose } \\
\text { Dopamine } \\
\text { Atropine } \\
\text { Adenocard }\end{array}$ & $\begin{array}{l}\text { Acetylsalicylic acid } \\
\text { Intravenous nitroglycerine } \\
\text { Antibiotics } \\
\text { Heparin } \\
\text { Pain medications } \\
\text { Respiratory treatments with beta agonists }\end{array}$ \\
\hline
\end{tabular}

\footnotetext{
*Adapted from [13].
} 
Table 2. Resource needs at the emergency department

\begin{tabular}{ll}
\hline Resource needs & No resource need \\
\hline Laboratory test values (blood, urine) & History, physical \\
Electrocardiography, X-ray imaging, computed tomography, & Point-of-care testing \\
magnetic resonance imaging, ultrasound angiography & \\
Intravenous fluids (hydration) & Saline or heparin lock \\
Intravenous fluids, intramuscular, or nebulized medications & $\begin{array}{l}\text { Per oral medications } \\
\text { Tetanus immunization }\end{array}$ \\
Specialty consultation & Prescription refills \\
Simple procedure $=1$ (Laceration repair, Foley catheter) & Phone call to primary care physician \\
Complex procedure $=2$ (conscious sedation) & Simple wound care (dressings, recheck) \\
& Crutches, splints, slings \\
\hline
\end{tabular}

Resource needs were defined by any investigations or treatments required during the ED visit (Table 2).

\section{Sample size calculation}

The sample size was calculated using the formula for cluster surveys. Based on the prevalence of patient category 2 of 3\% in 2013, the population size of $1,000,000$, and the confidence interval of $95 \%, 497$ patients were required.

\section{Statistical analyses}

Descriptive statistics were used to describe patients' characteristics. Discrimination performance between the 5- and 4-level triage was compared by using the area under a receiver operating characteristic (ROC) curve and concordance statistic on prediction of life saving intervention. Net reclassification improvement (NRI) of the 5-level ESI (version 4) over the 4-level triage was executed based on 2 categories of reclassification improvement (RI) according to LSI: $\mathrm{RI}_{\mathrm{LSI}}$ for users and $\mathrm{RI}_{\text {non-LSI }}$ for nonusers. The RI for users of LSI was the proportion of patients who were categorized at a higher level by the 5-level ESI than by the 4-level triage minus the proportion of patients who were categorized at a lower level by the ESI than by the 4-level triage. The RI for nonusers of LSI was the proportion of patients who were categorized at a lower level by the ESI than by the 4-level triage minus the proportion of patients who were categorized at a higher level by the ESI than by the 4-level triage. The NRI was the sum value of $\mathrm{RI}_{\mathrm{LSI}}$ and $\mathrm{RI}_{\text {non-LSI}}$.

\section{Results}

During the 4 month period of the study, there were
11,312 patients who visited the ED. Of those, 560 patients (4.95\%) met the study criteria, of whom 40 were excluded because of incomplete data (25), because they were referred patients (10), or because they were patients using EMS (5). In total, data from 520 patients were included in the analysis. The characteristics of these patients are shown in Table 3. None of the patients were defined as category 4 by the nurse triage because this category was one of the exclusion criteria.

\section{Characteristics of patients by the 4-level nurse triage}

The majority of patients were classified as class 2 emergency and 3 urgency (512 patients; 98.5\%). The median time for length of stay in the ED was higher for class 1 (9.5 h) than for class 2 or 3 . There were 307 patients who required more than 2 resources (59.0\%) and 32 patients (6.2\%) needed LSI, mostly in class 1 (62.5\%). Two patients in class 2 and 3 died. The details are shown in Table 4.

\section{Characteristics of patients by the ESI (Table 5)}

The majority of patients were classified as class 3 (205 patients; 39.4\%). The median time for length of stay in ED was highest in class 2. There were 32 patients $(6.2 \%)$ who needed lifesaving procedures. These patients were only in classes $1-3$. Two patients who died were classified as class 1.

\section{Comparison between the triage by nurses and ESI by $L S I$}

Discrimination performance

The areas under the ROC curves of the triage by ESI and nurses on LSI were significantly different $(P<0.001)$ (Figure 1) 
Table 3. Characteristics of patients visiting the ED who underwent both ESI and nursing triage assessment

\begin{tabular}{ll}
\hline Factors & $\begin{array}{l}\text { Numbers (percentage) } \\
\text { or median (range) }\end{array}$ \\
\hline Male sex & $216(41.5 \%)$ \\
Age, years & $51(0.4-97)$ \\
Trauma & $93(17.9)$ \\
Final status & \\
$\quad$ Discharge & $441(84.8)$ \\
Admitted & $50(9.6)$ \\
Operative room & $11(2.1)$ \\
Referred & $14(2.7)$ \\
Refused treatment & $3(0.58)$ \\
Death & $1(0.19)$ \\
Resource needs & \\
None & $97(18.7)$ \\
1 & $116(22.3)$ \\
$\geq 2$ & $307(59.0)$ \\
Life-saving intervention & $32(6.2)$ \\
Nursing triage (4 level) & \\
1 & $8(1.5)$ \\
2 & $180(34.6)$ \\
3 & $332(63.9)$ \\
4 & 0 \\
ESI triage (5 level) & $14(2.7)$ \\
1 & $92(17.7)$ \\
2 & $225(43.3)$ \\
4 & $116(22.3)$ \\
5 & $73(14.0)$ \\
Length of stay in ED, hours & $2.54(0.25-169)$ \\
& $2(0.38)$ \\
\hline & \\
\hline &
\end{tabular}

ESI, Emergency Severity Index; ED, emergency department

Table 4. Characteristics of patients by the 4-level nurse triage

\begin{tabular}{|c|c|c|c|}
\hline \multirow[t]{2}{*}{ Factors } & \multicolumn{3}{|c|}{ Category } \\
\hline & $\begin{array}{c}1 \text { Critical } \\
(n=8)\end{array}$ & $\begin{array}{l}2 \text { Emergency } \\
\quad(\mathrm{n}=180)\end{array}$ & $\begin{array}{l}3 \text { Urgent } \\
(n=332)\end{array}$ \\
\hline Median ED length of stay (range), hours & $9.50(0.75-153)$ & $3.94(0.5-169)$ & $2(0.25-124)$ \\
\hline \multicolumn{4}{|l|}{ Resource needs } \\
\hline None & 0 & $13(7.2 \%)$ & $84(25.3 \%)$ \\
\hline 1 & 0 & $27(15.0 \%)$ & $89(26.8 \%)$ \\
\hline$\geq 2$ & $8(100 \%)$ & $140(77.8 \%)$ & $159(47.9 \%)$ \\
\hline \multicolumn{4}{|l|}{ Final status } \\
\hline Discharged & $2(25 \%)$ & $143(79.4 \%)$ & $315(94.9 \%)$ \\
\hline Admitted to wards & $5(63 \%)$ & $23(12.8 \%)$ & $14(4.2 \%)$ \\
\hline Admitted to ICU & $1(13 \%)$ & $14(7.8 \%)$ & $3(0.9 \%)$ \\
\hline \multicolumn{4}{|l|}{ Life-saving intervention } \\
\hline Users $(\mathrm{n}=32)$ & $5(63 \%)$ & $24(13 \%)$ & $3(0.9 \%)$ \\
\hline Death & 0 & $1(0.6 \%)$ & $1(0.3 \%)$ \\
\hline
\end{tabular}

ED: emergency department; ICU: intensive care unit 
Table 5. Characteristics of all patients by ESI triage

\begin{tabular}{|c|c|c|c|c|c|}
\hline \multirow[t]{2}{*}{ Factors } & \multicolumn{5}{|c|}{ Classifications } \\
\hline & $\begin{array}{c}1 \\
(n=14)\end{array}$ & $\begin{array}{c}2 \\
(n=64)\end{array}$ & $\begin{array}{c}3 \\
(n=205)\end{array}$ & $\begin{array}{c}4 \\
(n=114)\end{array}$ & $\begin{array}{c}5 \\
(n=73)\end{array}$ \\
\hline Median ED length of stay (range), hours & $\begin{array}{l}4.83 \\
(0.75-153.5)\end{array}$ & $\begin{array}{l}8.67 \\
(0.5-169)\end{array}$ & $\begin{array}{l}3.41 \\
(0.5-124)\end{array}$ & $\begin{array}{l}1.62 \\
(0.41-34.17)\end{array}$ & $\begin{array}{l}0.86 \\
(0.25-4)\end{array}$ \\
\hline \multicolumn{6}{|l|}{ Resource needs } \\
\hline None & 0 & $2(2 \%)$ & $14(6 \%)$ & $17(15 \%)$ & $64(88 \%)$ \\
\hline 1 & 0 & $5(5 \%)$ & $32(14 \%)$ & $71(61 \%)$ & $8(11 \%)$ \\
\hline$\geq 2$ & 14(100) & $85(92 \%)$ & $179(80 \%)$ & $28(24 \%)$ & $1(1 \%)$ \\
\hline \multicolumn{6}{|l|}{ Final status } \\
\hline Discharged & $4(29 \%)$ & $64(69 \%)$ & $205(91 \%)$ & $114(99 \%)$ & $73(100 \%)$ \\
\hline Admitted to wards & $3(21 \%)$ & $20(22 \%)$ & $17(8 \%)$ & $2(2 \%)$ & 0 \\
\hline Admitted to ICU & $7(50 \%)$ & $8(9 \%)$ & $3(1 \%)$ & 0 & 0 \\
\hline \multicolumn{6}{|l|}{ Life-saving intervention } \\
\hline Users $(n=32)$ & $13(93 \%)$ & $17(19 \%)$ & $2(1 \%)$ & 0 & 0 \\
\hline Death & 2 & 0 & 0 & 0 & 0 \\
\hline
\end{tabular}

ESI: Emergency Severity Index, ED: emergency department, ICU: intensive care unit

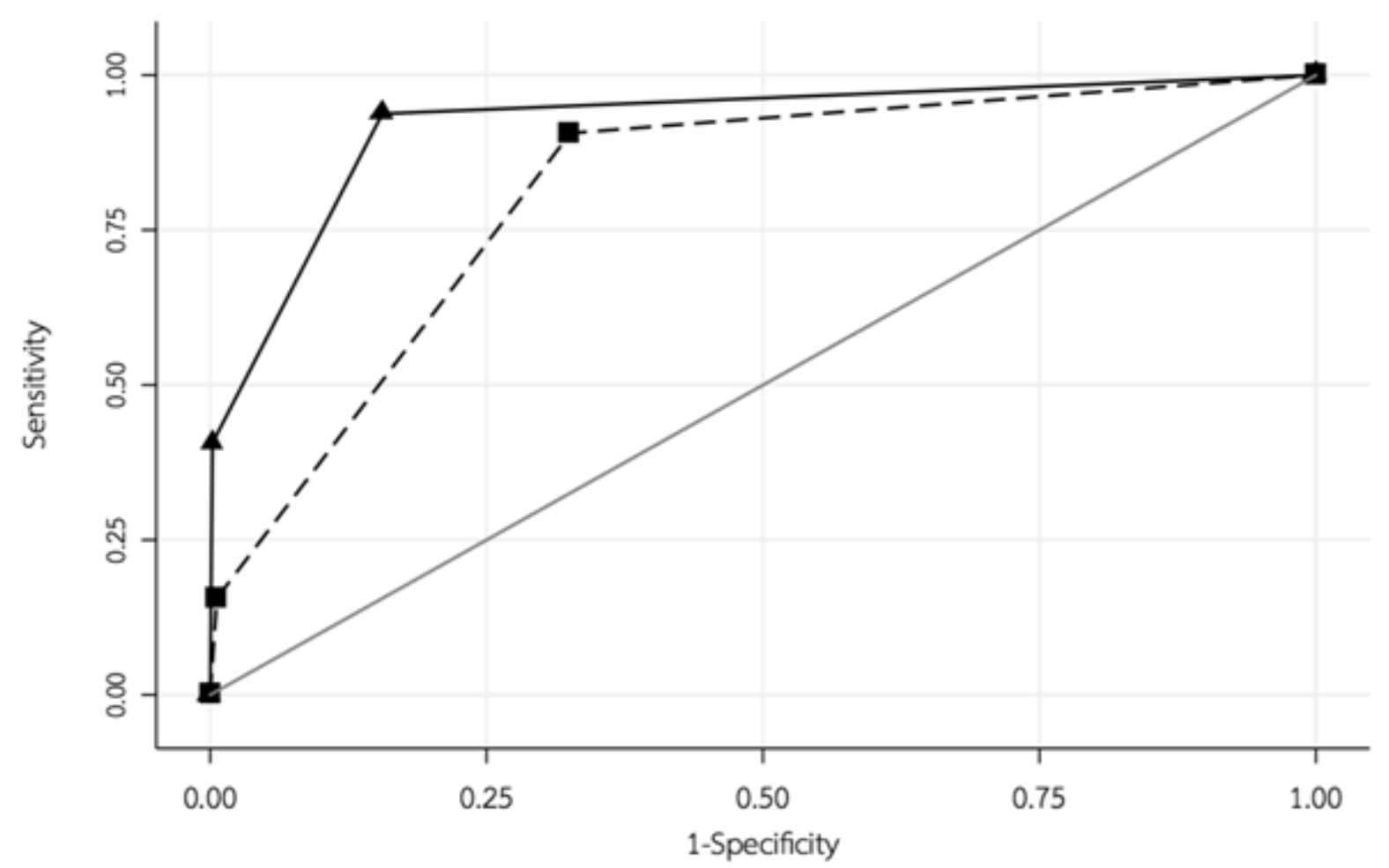

Figure 1. The receiver operating characteristic curves showed the use of life saving intervention when using the 5-level Emergency Severity Index triage (triangles unbroken line; AUC 92.2\%; 95\% CI 87.3\%, 96.9\%) versus the 4-level or nurse triage (squares dashed line; area under the curve (AUC) = 81.3\%; 95\% CI 75.2\%, 87.3\%). ROC AUCs were significantly different at a level of $P<0.001$ 


\section{Net reclassification improvement}

The concordant and disconcordant numbers of patients by the nurse and ESI triage categorized by LSI are shown in Table 6.

Among the group using an LSI (32 patients), 9 patients, who had been classified by the nurse triage, were reclassified to a higher class by the ESI and 1 patient was reclassified to a lower class. The reclassification improvement was (9-1)/32 or $25 \%$.

For those who did not receive lifesaving intervention (488 patients), 15 patients who had been classified by the nurse triage were reclassified to a lower class by the ESI and 100 patients were reclassified to a lower class. The reclassification improvement was (100-15)/488 or $17.4 \%$. The net reclassification improvement was $42.4 \%$ (95\%CI 0.226, 0.622).

\section{Discussion}

This study showed that the 5-level ESI triage is more accurate than the 4-level assessment tool used by nurses at Ramathibodi Hospital to predict the necessity for LSI. The 5-level tool had better discriminatory performance (Figure 1) and reclassification improvement (Table 6) than that of the 4-level tool.

The larger area under the ROC curve by the ESI (92.2\% vs $81.3 \%$ ) indicated the greater accuracy of the 5-level assessment tool to predict the necessity for life-saving intervention over the 4-level tool (Figure 1). A head-to-head comparison of both tools showed that $68.8 \%$ in the life-saving-intervention group and $76.4 \%$ in the non-life-saving-intervention group were concordant. However, the net benefit for reclassification improvement was 42.4\% (95\%CI: $0.226,0.622)$. These results implied that $42.4 \%$ of patients may be either overrated or under-rated by the 4-level tool compared with the ESI in predicting the occurrence of serious life-saving intervention. Also of note was that the 2 patients who died were correctly identified by the ESI as class 1 , while the 4level categorized them as class 2 or 3 .

New information regarding assessment of severity in the ED by this study included (1) a comparison of the 5-level versus 4-level triage (previous studies reported on the 5-level versus 3-level [3], (2) the accuracy of the 5-level ESI (previous studies showed reliability and validity, but not accuracy [9, 12], (3) additional outcomes (previous studies showed correlation of the ESI and several outcomes such as survival, resource use, and length of stay at the ED, but the not life-saving intervention [14-16].

There were some limitations to this study. First, each tool was used by a different group of assessors. The 4-level triage was performed by nurses in the ED and the ESI was conducted by emergency department physicians. Nevertheless, the nurses who performed the triage were experienced. Second, patients enrolled in the study were all general patients at the ED, not a specific study population such as trauma or elderly patients $[13,17]$. Third, the outcome was primarily focused only on life-saving intervention because of the low mortality rate $(0.38 \%)$. Finally, the study was conducted at the ED of a university hospital. The results may not apply to all hospitals, such as primary care hospitals. Further studies are needed to examine the effects in specific study populations and other hospital settings.

Table 6. Reclassification improvement of receivers and non-receivers of life-saving interventions (LSI) and net reclassification improvement

\begin{tabular}{|c|c|c|c|c|c|}
\hline \multirow[t]{2}{*}{ LSIuse } & \multirow[t]{2}{*}{4 level triage } & \multicolumn{3}{|c|}{ ESI triage } & \multirow[t]{2}{*}{ Total } \\
\hline & & Level 3 & Level 2 & Level 1 & \\
\hline \multirow[t]{5}{*}{ Yes } & Level 3 & 2 & 0 & 1 & 3 \\
\hline & Level 2 & 0 & 16 & 8 & 24 \\
\hline & Level 1 & 0 & 1 & 4 & 5 \\
\hline & Total & 2 & 17 & 13 & 32 \\
\hline & \multicolumn{5}{|c|}{ Reclassification improvement $_{\mathrm{LSI}}=(9-1) / 32=0.250$} \\
\hline \multirow[t]{5}{*}{ No } & Level 3 & 314 & 15 & 0 & 329 \\
\hline & Level 2 & 98 & 58 & 0 & 156 \\
\hline & Level 1 & 0 & 2 & 1 & 3 \\
\hline & Total & 412 & 75 & 1 & 488 \\
\hline & \multicolumn{5}{|c|}{ Reclassification improvement $_{\text {non-LSI }}=(100-15) / 488=0.174$} \\
\hline
\end{tabular}

Net reclassification improvement $(\mathrm{NRI})=0.424(95 \% \mathrm{CI}: 0.226,0.622)(P<0.001)$ 


\section{Conclusion}

The 5-level emergency severity index is more accurate than 4-level triage in terms of life-saving intervention.

\section{Acknowledgments}

The authors thank Mr. Dylan Southard, Research Affairs, Faculty of Medicine, Khon Kaen University, Thailand, for his English language editing of the manuscript. This study was supported by TRF Senior Research Scholar Grant from the Thailand Research Fund (TRF grant No. RTA5880001), and the Higher Education Research Promotion and National Research University Project of Thailand, Office of the Higher Education Commission, Thailand, through the Health Cluster (SHeP-GMS), Khon Kaen University and Thailand Research Fund (IRG 5780016).

\section{Conflict of interest statement}

The authors declare that there is no conflict of interest in this research.

\section{References}

1. Wuerz RC, Milne LW, Eitel DR, Travers D, Gilboy N. Reliability and validity of a new five-level triage instrument. Acad Emerg Med. 2000; 7:236-42.

2. Murray M, Bullard M, Grafstein E; for the CTAS and CEDIS National Working Groups. Revisions to the Canadian Emergency Department Triage and Acuity Scale Implementation Guidelines. CJEM. 2004; 6: 421-7.

3. Travers DA, Waller AE, Bowling JM, Flowers D, Tintinalli J. Five-level triage system more effective than three-level in tertiary emergency department. J Emerg Nurs. 2002; 28:395-400.

4. Jelinek GA, Little M. Inter-rater reliability of the National Triage Scale over 11,500 simulated occasions of triage. Emerg Med. 1996; 8:226-30.

5. Beveridge R, Ducharme J, Janes L, Beaulieu S, Walter S. Reliability of the Canadian emergency department triage and acuity scale: interrater agreement. Ann Emerg Med. 1999; 34:155-9.

6. Richardson D. No relationship between emergency department activity and triage categorization. Acad Emerg Med. 1998; 6:141-5.

7. Downey LV, Zun LS, Burke T. Comparison of
Canadian triage acuity scale to Australian Emergency Mental Health Scale triage system for psychiatric patients. Int Emerg Nurs. 2015; 23:138-43.

8. Canadian Association of Emergency Physicians. Canadian Emergency Department Triage and acuity scale implementation guidelines. J Can Assoc Emerg Phys. 1999; 1:S1-16.

9. Wurez RC, Milne LW, Eitel DR, Travers D, Gilboy N. Reliability and validity of a new five-level triage instrument. Acad Emerg Med. 2000; 7236-2.

10. Wurez RC, Travers D, Gilboy N, Eitel DR, Rosenau A, Yazhari R. Implementation and refinement of the emergency severity index. Acad Emerg Med. 2001; 8: 170-6.

11. ESI Triage Study Group Wurez R. Emergency severity index triage category is associated with six-month survival. Acad Emerg Med. 2001; 8:61-4.

12. Tanabe P, Travers D, Rosenau A, Gilboy N, Wuerz R. The Emergency Severity Index Triage algorithm version 2 is reliable and valid. Acad Emerg Med. 2003; 10:1070-80.

13. Platts-Mills TF, Travers D, Biese K, McCall B, Kizer S, La Mantia, Busby JW, Cairns CB. Accuracy of the Emergency Severity Triage instrument for identifying elder emergency department patients receiving an immediate life-saving intervention. Acad Emerg Med. 2010; 17:238-43.

14. Chi CJ, Huang CM. Comparison of the Emergency Severity Index (ESI) and the Taiwan Triage System in predicting resource utilization. J Formos Med Assoc. 2006; 105:617-25.

15. Wuerz R. Emergency Severity Index triage category is associated with six-month survival. ESI triage study group. Acad Emerg Med. 2001; 8:61-4.

16. Grossman FF, Nickel CH, Christ M, Schneider K, Spirig R, Bingisser R. Transporting clinical tools to new settings: Cultural adaptation and validation of the Emergency Severity Index in German. Ann Emerg Med. 20711; 57:257-64.

16. Storm-Versloot MN, Ubbink D T, Kappelhof J, Luitse JSK. Comparison of an informally structured triage system, the emergency severity index, and the Manchester triage system to distinguish patient priority in the Emergency Department. Acad Emerg Med. 2011; 18:822-9. 